\title{
Objetos de Aprendizagem em Scratch para Estudo de Saneamento Básico: Percepções de Alunos e Professores
}

\author{
Aline M. dos S. Silva ${ }^{1}$, Deiz Amara S. de S. Moraes $^{1}$, Silvia Cristina F. Batista ${ }^{1}$ \\ ${ }^{1}$ Instituto Federal Fluminense Campus Campos-Centro \\ Rua Dr. Siqueira, 273. Parque Dom Bosco. CEP: 28030-130. Campos dos \\ Goytacazes/RJ \\ alinemarcelino@zipmail.com, deizamara@hotmail.com, silviac@iff.edu.br
}

\begin{abstract}
This article aims to analyze the perception of students and teachers on three learning objects developed in the Scratch programming environment. These resources were developed by the authors of the article and are intended for the studying of issues of sanitation. For data collection a case study with students of the 5th year of elementary school from a public school was held, as was promoted a research with five teachers this school year. In general, learning objects were considered important tools for teaching and learning, although suggestions on how to improve them have also been identified.
\end{abstract}

Resumo. Este artigo busca analisar a percepção de alunos e professores em relação a três objetos de aprendizagem desenvolvidos no ambiente de programação Scratch. Tais recursos foram elaborados pelas autoras do artigo e são destinados ao estudo de temas de saneamento básico. Para levantamento dos dados foi realizado um estudo de caso com alunos do $5^{\circ}$ ano do Ensino Fundamental de uma escola municipal, assim como foi promovida uma pesquisa com cinco professores desse ano de escolaridade. De maneira geral, os objetos de aprendizagem foram considerados importantes instrumentos para o processo de ensino e aprendizagem, embora sugestões para o aprimoramento dos mesmos também tenham sido apontadas.

\section{Introdução}

De acordo com o Sistema Nacional de Informações sobre Saneamento (SNIS) 2010, apenas 53,5\% da população urbana brasileira tem acesso à coleta e 37,9\% ao tratamento de esgotos, ocasionando, desta forma, a contaminação de rios, mananciais, praias e solo. Consequentemente, a saúde da população fica prejudicada, em decorrência das doenças geradas pela falta de tratamento de água e esgoto [Trata Brasil 2012]. O conteúdo de saneamento básico é parte integrante da área de Educação Ambiental e, diante dos dados apresentados, verifica-se a importância de realizar trabalhos relacionados a esse tema, na busca de uma sensibilização ambiental.

Nesse sentido, as Tecnologias Digitais (TD) podem trazer contribuições ao favorecerem experimentações e investigações. Como defendido por Rodrigues e Colesanti (2008), essas tecnologias implicam mudanças de atitudes, valores e comportamentos, ao aproximarem aspectos pedagógicos e necessidades das novas gerações. Dessa forma, as mudanças possibilitadas pelas TD são importantes para o desenvolvimento de trabalhos na área de Educação Ambiental.

Dentre os diversos recursos que podem apoiar ações pedagógicas, destaca-se, no presente trabalho, a linguagem de programação Scratch. Trata-se de um projeto do 
grupo Lifelong Kindergarten do Media Lab do Massachusetts Institute of Technology (MIT) projetado, especificamente, para fins educacionais, tendo em vista jovens com idades entre oito e dezesseis anos. No entanto, a linguagem tem sido usada por pessoas de todas as idades [Resnick et al. 2009]. O Scratch é um recurso gratuito e fácil de utilizar, já que não é necessário digitar comandos ao realizar a programação [Pensamento Digital 2012]. No mesmo, a criação de Objetos de Aprendizagem (OA) torna-se menos complexa, uma vez que é feita por meio da ação de arrastar e encaixar blocos que possuem funções específicas. A Figura 1 mostra a tela inicial do ambiente de programação $S c r a t c h$, na versão $2.0^{1}$, em português.

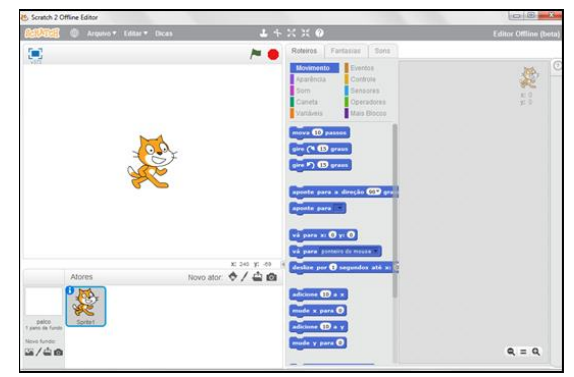

Figura 1. Ambiente de programação do Scratch - versão 2.0 - em português

Embora já esteja em sua versão 2.0, a versão $1.4^{2}$ foi a utilizada no desenvolvimento de três OA. Segundo Macêdo et al. (2007), os OA são alternativas que enriquecem as práticas pedagógicas, além de proporcionarem ao professor estratégias para o acompanhamento do desenvolvimento do aluno.

Os referidos OA foram elaborados pelas autoras deste artigo, tendo em vista o estudo de temas de saneamento básico. Para experimentação e avaliação dos mesmos foi realizado um estudo de caso com uma turma de $5^{\circ}$ ano de Ensino Fundamental de uma instituição do município de Campos dos Goytacazes/RJ. Além disso, promoveu-se uma pesquisa com cinco professores desse ano de escolaridade.

Buscou-se, dessa forma, captar a percepção, tanto de alunos quanto de professores, sobre aspectos relacionados a questões operacionais, de usabilidade, pedagógicas e de conteúdo, tendo em vista analisar se os objetos desenvolvidos podem ser importantes como recursos educacionais. Como defendido por Almeida et al. (2012), um grande desafio para professores e pesquisadores, ao utilizarem OA, é saber se os mesmos são eficazes e atendem aos critérios de qualidade para o processo de ensino e aprendizagem. Também focalizando essa questão, Tarouco (2004) afirma que as avaliações podem orientar uma melhor utilização dos OA e fornecer um feedback para os desenvolvedores, de modo que os recursos possam ser aprimorados. Batista et al. (2004) também destacam a importância da avaliação de recursos digitais educacionais ressaltando que posturas críticas podem contribuir para a seleção de ferramentas mais adequadas e melhor aproveitamento das potencialidades das mesmas.

Tendo em vista descrever e analisar a pesquisa promovida, os OA desenvolvidos são apresentados na seção 2 deste artigo. Na seção 3, relatam-se os procedimentos metodológicos adotados na pesquisa e, na seção 4, são analisados os resultados obtidos. Finalizando, na seção 5, são tecidas algumas considerações sobre a pesquisa realizada.

\footnotetext{
${ }^{1}<$ http://scratch.mit.edu/projects/editor/?tip_bar=getStarted $>$.

$2<$ http://scratch.mit.edu/scratch_1.4/>.
} 


\section{Objetos de aprendizagem desenvolvidos no Scratch}

Os OA desenvolvidos são apresentados a seguir. São eles: uma história, um jogo e um quiz. Destaca-se que todos foram disponibilizados no portal do Scratch ${ }^{3}$.

\subsection{História}

O primeiro OA elaborado foi uma história na qual foram apresentados tópicos sobre o Saneamento Básico. Foram ressaltados aspectos relacionados à água, ao lixo e ao esgoto. Pretende-se, por meio da história, que o estudante se sensibilize em relação à Educação Ambiental e perceba a importância de exercer seu papel como multiplicador no contexto social em que vive. A Figura 2 ilustra um trecho da história.

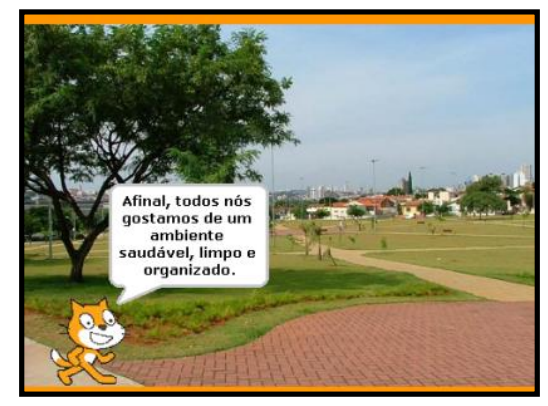

Figura 2. Tela do OA história

O objetivo da história é introduzir o conteúdo a ser estudado. Na construção da mesma foram utilizadas imagens, textos e um personagem, um gato, chamado Saninho. Inicialmente, o personagem se identifica e convida os estudantes a conhecerem o conteúdo de Saneamento Básico. Os alunos têm a possibilidade de mover o personagem, no decorrer da história, utilizando as setas do teclado do computador. A história só é iniciada quando o aluno pressiona a tecla Espaço no teclado.

Após o estudante iniciar a história, as imagens aparecem na tela com suas devidas explicações sobre o conteúdo. A cada imagem atribuiu-se um tempo de exibição, de acordo com o tamanho da mensagem exibida. Procurou-se colocar um tempo adequado para a leitura de todos os alunos. Foram utilizadas quinze imagens diversas sobre os problemas relacionados à água, ao esgoto e ao lixo. As imagens e os respectivos textos destacam a importância do estudo sobre o tema.

\subsection{Quiz}

O quiz, composto de dez questões com opções de respostas, tem como objetivo avaliar conhecimentos sobre saneamento básico.

O aluno deverá clicar na bandeira verde no alto da tela para começar o quiz. A seguir, deverá ler atentamente as mensagens mostradas pelo personagem. Cada pergunta possui três opções de respostas. $\mathrm{O}$ aluno deve responder com a letra correspondente à resposta certa. Caso acerte, recebe uma mensagem de acerto. Caso erre, recebe uma mensagem orientando a rever a sua resposta e tem a possibilidade de tentar outra vez. Após a segunda tentativa, o aluno recebe outra mensagem, que pode ser de acerto ou de

\footnotetext{
$3<$ http://scratch.mit.edu/projects/15047021/>; <http://scratch.mit.edu/projects/15047143/>; $<$ http://scratch.mit.edu/projects/15047076/>.
} 
erro. O estudante só poderá tentar responder cada pergunta duas vezes.

Sobre a pontuação, o valor depende da quantidade de tentativas. Se o estudante acertar na primeira tentativa receberá dez pontos e na segunda, o valor será de cinco pontos. O aluno poderá observar a pontuação de cada questão no alto da tela, bem como a pontuação total ao término do quiz.

O quiz também utiliza o mesmo personagem da história para apresentação das perguntas. A movimentação deste é feita por meio das setas do teclado do computador. A Figura 3 mostra a tela de finalização do quiz.

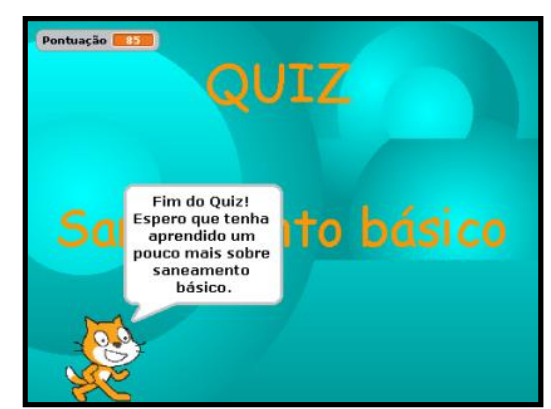

Figura 3. Tela de finalização do quiz

\subsection{Jogo}

O jogo tem por objetivo abordar a importância da reciclagem, de forma lúdica. O mesmo é composto de objetos variados, representando tipos diferentes de lixo, os quais o aluno deverá levar até a lixeira correta de coleta seletiva.

Foram utilizados oito objetos de diferentes materiais enfatizando a variedade de lixo com os quais os estudantes lidam em seu cotidiano. No jogo, foram apresentados quatro tipos de lixeira mais comuns, uma vez que o OA é destinado a alunos do Ensino Fundamental, tendo em vista um contato inicial com o tema coleta seletiva.

O estudante receberá uma mensagem inicial orientando-o a levar o lixo até a lixeira correta, de acordo com o material, conforme ilustra a Figura 4.

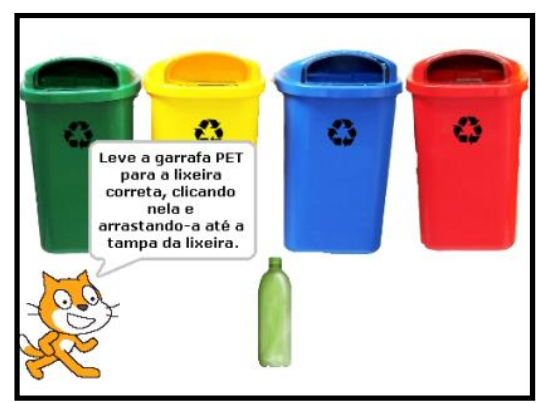

Figura 4 - Tela do jogo Coleta Seletiva

Os OA apresentados foram experimentados em um estudo de caso e avaliados por professores, como descrito na seção seguinte.

\section{Procedimentos metodológicos}

Os OA história, quiz e jogo foram experimentados em um estudo de caso com alunos de uma turma do $5^{\circ}$ ano do Ensino Fundamental, de uma instituição municipal em Campos dos Goytacazes/RJ. 
A escolha deste ano de escolaridade se deu pelo fato do currículo desta série apresentar o conteúdo Saneamento Básico, trabalhado nos OA. A escola considerada nesse estudo de caso é a instituição de ensino em que trabalha uma das autoras deste artigo. A mesma conta com um laboratório de informática e possui uma única turma de $5^{\circ}$ ano, na qual se realizou o estudo de caso, em onze de setembro de 2013 . O mesmo foi promovido no horário regular de aula dos alunos, com duração de quatro aulas com 50 minutos cada.

Os instrumentos de coleta de dados utilizados foram: listas de exercícios de préteste e pós-teste, observação e questionário. As etapas do estudo de caso podem ser resumidas da seguinte forma: i) aplicação de pré-teste e utilização do OA história (aula 1); ii) utilização dos OA quiz e jogo (aulas 2 e 3); iii) aplicação de pós-teste e questionário de avaliação sobre a aula e sobre os recursos (aula 4).

Após a realização do estudo de caso, os OA foram avaliados por cinco professores que trabalham com turmas do $5^{\circ}$ ano do Ensino Fundamental em outras instituições de ensino. A opção por professores de outras escolas foi decorrente do pequeno número de professores do $5^{\circ}$ ano da escola considerada no estudo de caso.

$\mathrm{Na}$ pesquisa com os professores, utilizou-se um questionário como instrumento de coleta de dados. No mesmo, os OA foram avaliados quanto a aspectos operacionais, de usabilidade, pedagógicos e de conteúdo.

\section{Resultados e discussão}

No estudo de caso realizado, inicialmente, os alunos foram orientados a responder à lista de exercícios do pré-teste e, em seguida, foram levados para o laboratório de informática. Os OA história, quiz e jogo foram utilizados nesta sequência e sob a mediação das professoras, duas primeiras autoras deste artigo. Por fim, houve a aplicação de pós-teste e do questionário de avaliação sobre a aula e sobre os recursos.

Os resultados analisados por meio dos instrumentos de coleta de dados e pela observação permitiram verificar a percepção dos alunos sobre a proposta pedagógica baseada no uso de OA. Verificou-se um avanço sobre o conhecimento do conteúdo de saneamento básico, com base na análise das respostas do pré-teste e pós-teste. As respostas do questionário evidenciaram que a proposta pedagógica apoiada na utilização dos OA contribuiu para a compreensão do conteúdo. Durante as aulas, os alunos também sinalizaram boa aceitação dos OA, ao pedirem para utilizá-los novamente e ao relatarem que o uso destes foi o que mais gostaram.

Nos questionários, os estudantes apresentaram suas justificativas sobre a aceitação da proposta pedagógica. As mensagens, a seguir, destacam esse resultado.

Porque a aula teve brincadeiras e nós ainda aprendemos (Estudante C).

Porque eu gostei do joguinho. Eu joguei muito e estava muito legal (Estudante E).

Os dados obtidos nos questionários também evidenciaram que 68,4\% dos estudantes mencionaram que a utilização dos $\mathrm{OA}$ foi o que mais gostaram da aula. Corroborando essa visão, destaca-se a mensagem do estudante P: "Das brincadeiras no computador". 
De maneira geral, foi possível observar que os alunos avaliaram positivamente os OA desenvolvidos. A maioria não propôs mudanças para os mesmos, porém alguns sugeriram aumentá-los, colocando mais questões e brincadeiras, como nas frases "aumentar o jogo, colocando mais lixeiras" e "colocar o boneco lutando". Alguns alunos sugeriram aumentar o tempo de leitura das mensagens no OA história e diminuir este tempo no OA jogo.

Após o estudo de caso, foi promovida a pesquisa com os professores, por meio de questionário. No mesmo, era preciso assinalar, diante das afirmativas apresentadas, uma das opções: DC "discordo completamente", D "discordo", NCND "não discordo nem concordo", C "concordo" e CC "concordo completamente". Além disso, era possível registrar observações sobre os OA. A análise desses dados evidenciou a valorização dos objetos como instrumentos mediadores e motivadores para o processo de ensino e aprendizagem, como descrito a seguir, a partir das Tabelas 1, 2 e 3.

Sobre a avaliação do OA história (Tabela 1), nas questões operacionais, a maioria dos professores concordou completamente com a afirmativa sobre $\mathrm{o}$ funcionamento correto do programa e também em relação à adequação do tempo de cada mensagem.

Tabela 1. Avaliação do OA história - professores

\begin{tabular}{|c|c|c|c|c|c|}
\hline Afirmativas & $\begin{array}{c}\mathrm{DC} \\
\%\end{array}$ & $\begin{array}{l}\mathbf{D} \\
\%\end{array}$ & $\begin{array}{c}\text { NC ND } \\
\%\end{array}$ & $\begin{array}{l}\mathrm{C} \\
\%\end{array}$ & $\begin{array}{c}\mathrm{CC} \\
\%\end{array}$ \\
\hline \multicolumn{6}{|c|}{ Questões operacionais } \\
\hline $\begin{array}{l}\text { O programa funcionou corretamente } \\
\text { durante o teste. }\end{array}$ & 0 & 0 & 0 & 20 & 80 \\
\hline O tempo de cada mensagem é adequado. & 0 & 0 & 0 & 20 & 80 \\
\hline \multicolumn{6}{|c|}{ Usabilidade e questões pedagógicas } \\
\hline É motivador. & 0 & 0 & 0 & 20 & 80 \\
\hline É interativo. & 0 & 40 & 0 & 0 & 60 \\
\hline Projeto gráfico de boa qualidade. & 0 & 0 & 20 & 40 & 40 \\
\hline \multicolumn{6}{|c|}{ Conteúdo } \\
\hline É claro e conciso. & 0 & 0 & 0 & 0 & 100 \\
\hline Aborda conteúdo relevante. & 0 & 0 & 0 & 0 & 100 \\
\hline Os conceitos apresentados são corretos. & 0 & 0 & 0 & 0 & 100 \\
\hline
\end{tabular}

Quanto à usabilidade ${ }^{4}$, a maior parte dos professores considerou como sendo boa a qualidade do projeto gráfico do OA história. O conteúdo do mesmo foi considerado claro, conciso, correto e de relevância por todos os professores avaliadores.

No entanto, observa-se que um percentual de $40 \%$ discordou da interatividade do OA história e $20 \%$ manteve-se neutro em relação ao seu projeto gráfico. Tais percentuais estão coerentes com as sugestões dadas por alguns dos professores (comentadas mais adiante, nesta seção) e serão analisados em termos de melhorias a serem promovidas nesse OA.

A Tabela 2 apresenta a avaliação do OA quiz. Quanto às questões operacionais, todos os professores concordaram completamente com a afirmativa sobre $\mathrm{O}$ funcionamento correto do $\mathrm{OA}$, assim como, em relação à adequação do tempo das

4 O termo usabilidade pode ser definido como a "capacidade do produto de software de ser compreendido, aprendido, operado e atraente ao usuário, quando usado sob condições especificadas" [ABNT 2003 p. 9]. 
mensagens. Considerando conjuntamente as opções Concordo e Concordo Completamente, observa-se que todos os professores consideraram o OA quiz fácil de usar, motivador, interativo e com projeto gráfico de boa qualidade. Os resultados também foram positivos sobre o conteúdo deste OA. Em relação a ter instruções claras, $20 \%$ dos professores optaram por uma posição neutra.

Tabela 2. Avaliação do OA quiz - professores

\begin{tabular}{|c|c|c|c|c|c|}
\hline Afirmativas & $\begin{array}{c}\mathrm{DC} \\
\%\end{array}$ & $\begin{array}{l}\mathrm{D} \\
\%\end{array}$ & $\begin{array}{c}\text { NC ND } \\
\%\end{array}$ & $\begin{array}{l}\mathbf{C} \\
\%\end{array}$ & $\begin{array}{c}\mathrm{CC} \\
\%\end{array}$ \\
\hline \multicolumn{6}{|c|}{ Questões operacionais } \\
\hline $\begin{array}{l}\text { O programa funcionou corretamente durante } \\
\text { o teste. }\end{array}$ & 0 & 0 & 0 & 0 & 100 \\
\hline O tempo de cada mensagem é adequado. & 0 & 0 & 0 & 0 & 100 \\
\hline \multicolumn{6}{|c|}{ Usabilidade e questões pedagógicas } \\
\hline É fácil de usar. & 0 & 0 & 0 & 40 & 60 \\
\hline Têm instruções claras. & 0 & 0 & 20 & 20 & 60 \\
\hline É motivador. & 0 & 0 & 0 & 20 & 80 \\
\hline É interativo. & 0 & 0 & 0 & 40 & 60 \\
\hline Projeto gráfico de boa qualidade. & 0 & 0 & 0 & 40 & 60 \\
\hline \multicolumn{6}{|c|}{ Conteúdo } \\
\hline É claro e conciso. & 0 & 0 & 0 & 40 & 60 \\
\hline Aborda conteúdo relevante. & 0 & 0 & 0 & 20 & 80 \\
\hline Os conceitos apresentados são corretos. & 0 & 0 & 0 & 0 & 100 \\
\hline
\end{tabular}

A Tabela 3 apresenta a avaliação do jogo. Em relação às questões consideradas destaca-se uma boa avaliação do mesmo. No entanto, um percentual de $20 \%$ dos professores julgou que o tempo da mensagem do jogo não foi adequado, discordando completamente em relação à afirmativa.

Tabela 3. Avaliação do OA jogo - professores

\begin{tabular}{|c|c|c|c|c|c|}
\hline Afirmativas & $\begin{array}{c}\mathrm{DC} \\
\%\end{array}$ & $\begin{array}{l}\text { D } \\
\%\end{array}$ & $\begin{array}{c}\text { NC ND } \\
\%\end{array}$ & $\begin{array}{l}\mathrm{C} \\
\%\end{array}$ & $\begin{array}{c}\mathrm{CC} \\
\%\end{array}$ \\
\hline \multicolumn{6}{|c|}{ Questões operacionais } \\
\hline $\begin{array}{l}\text { O programa funcionou corretamente durante o } \\
\text { teste. }\end{array}$ & 0 & 0 & 0 & 60 & 40 \\
\hline O tempo de cada mensagem é adequado. & 20 & 0 & 0 & 0 & 80 \\
\hline \multicolumn{6}{|c|}{ Usabilidade e questões pedagógicas } \\
\hline É fácil de usar. & 0 & 0 & 20 & 20 & 60 \\
\hline Têm instruções claras. & 0 & 0 & 20 & 0 & 80 \\
\hline É motivador. & 0 & 0 & 0 & 20 & 80 \\
\hline É interativo. & 0 & 0 & 0 & 20 & 80 \\
\hline Projeto gráfico de boa qualidade. & 0 & 0 & 20 & 0 & 80 \\
\hline \multicolumn{6}{|c|}{ Conteúdo } \\
\hline É claro e conciso. & 0 & 0 & 20 & 60 & 20 \\
\hline Aborda conteúdo relevante. & 0 & 0 & 0 & 0 & 100 \\
\hline Os conceitos apresentados são corretos. & 0 & 0 & 0 & 0 & 100 \\
\hline
\end{tabular}

De acordo com os dados da Tabela 3, 20\% dos professores não concordaram e nem discordaram dos pontos relacionados à usabilidade e da afirmação sobre o conteúdo do OA jogo ser claro e conciso. Tais aspectos também serão analisados em busca de melhorias. 
Neste mesmo questionário, os professores puderam registrar comentários e observações sobre os OA. A seguir, são destacadas três falas sobre o OA história:

Programa inteiramente participativo, interessante e motivador (Professor A).

A parte teórica não permite interatividade, o aluno apenas lê os textos, não pode mudar ou acrescentar nada. O programa é bom, proporciona aprendizagem de uma maneira lúdica e esclarecedora (Professor D).

O programa funcionou muito bem durante todo o processo de exibição das informações, inclusive com a tela cheia. Em relação às questões abordadas aqui, creio que não há propriamente interatividade além daquilo que se espera quando alguém pode manipular um programa de um computador e ler. Basicamente isto, pois o aluno pode deixá-lo correr sem que haja uma maior interação. Sobre o projeto gráfico, creio que poderiam ser observados alguns itens: seria interessante que o gato pudesse se movimentar, de forma a se postar em posições onde as imagens de fundo não fossem cobertas, além disso, só a transição das imagens não acrescentam muito e se o gato só se movimentasse, causaria um efeito mais interessante e chamativo ao programa (Professor E).

A fala do Professor A ressalta a motivação proporcionada pelo OA, também evidenciada pela maioria dos alunos ao mencionarem que gostaram do uso dos objetos em aula.

As mensagens dos professores $\mathrm{D}$ e $\mathrm{E}$ também foram destacadas, pois apresentaram sugestões para a melhoria dos OA. A aprendizagem de forma lúdica, mencionada na fala do Professor D, também foi verificada nas mensagens extraídas dos questionários dos alunos sobre o uso dos OA na aula, como mostra a fala do Estudante B: "Porque é legal, divertido".

Já o professor $\mathrm{E}$ apresentou sugestões em relação à interatividade, como mudanças na movimentação do personagem deste OA. A interatividade pode ser definida como "a extensão em que os usuários podem participar modificando a forma e o conteúdo do ambiente mediado em tempo real" [Steuer 1992 p. 1 apud Primo e Cassol 1999 p. 68].

A seguir, as observações destacadas sobre o OA quiz:

Conteúdo relevante, incentivador e participativo. Parabéns! (Professor A).

O programa é bom, porém o aluno não tem autonomia para mudar de tela (Professor B).

O fato de o gato poder ser movimentado durante o jogo é um ponto interessante. O texto do jogo é bem objetivo, o que favorece uma leitura rápida e a compreensão dos conceitos abordados. Este jogo é muito interessante, mas gostaria de sugerir que houvesse outras frases de estímulo quando o jogador acerta alguma opção, para que não fique aquela impressão de algo automatizado (Professor E).

Os professores valorizaram vários aspectos do OA quiz, como o conteúdo e a motivação, porém destacaram que a interação poderia ser maior se o aluno fosse mais autônomo. Foram sugeridas mudanças para as mensagens de erro e acerto exibidas no 
quiz. Segundo o professor E, estas mensagens poderiam ser diversificadas, a fim de não deixar o OA automatizado, ou seja, com o objetivo de torná-lo mais motivador e interativo. É importante ressaltar que, embora o professor E tenha utilizado o termo "jogo" em seus comentários, o mesmo se referia ao OA quiz. Uma maior interação também foi requerida pelos estudantes. Mesmo com as falhas apontadas, o OA quiz foi considerado o recurso que os alunos mais gostaram.

Por último, são apresentados três comentários dos professores sobre o OA jogo:

Bastante interessante, lúdico e participativo (Professor A).

Seria necessário acrescentar a existência da lixeira marrom usada para armazenar o lixo orgânico (Professor D).

Creio que deveria haver mais um tempo para que o usuário consiga ler as instruções, especialmente para o público a que é destinado, que muitas vezes apresenta sérios problemas de leitura e interpretação. Em relação ao conteúdo, é extremamente relevante e, de forma simples, serve para avaliar o conhecimento prévio do aluno sobre o tema; também instrui caso o aluno não saiba do assunto (Professor E).

As falas destacadas sobre o OA jogo também apresentaram indícios de que o mesmo é um instrumento motivador e mediador no processo de ensino e aprendizagem. O Professor D sugeriu acrescentar no jogo mais uma lixeira de coleta seletiva. O aumento do número de lixeiras também foi sugerido pelos alunos, a fim de ampliar a sua abrangência, o que pode ser uma evidência da aceitação deste OA. Para o Professor E, o tempo de exibição das mensagens no jogo deveria ser aumentado, porém os alunos sugeriram que este tempo fosse diminuído. O professor levou em consideração as dificuldades de leitura e interpretação, geralmente observadas neste ano de escolaridade e em outros do Ensino Fundamental, porém a turma demonstrou, por meio da observação realizada, facilidade em relação à leitura, o que justifica a fala dos alunos sobre o tempo das mensagens do OA jogo.

As sugestões dadas pelos professores foram de grande contribuição para esta pesquisa, assim como a dos alunos. As análises serão realizadas, e posteriormente, as melhorias serão promovidas nos OA. As alterações podem ser feitas diretamente no site do Scratch, no qual os OA foram disponibilizados.

\section{Considerações Finais}

O estudo de caso realizado permitiu conhecer e investigar a percepção dos alunos sobre os três OA desenvolvidos. Verificou-se a boa aceitação dos mesmos, pelos estudantes, por meio da motivação observada nas aulas e das respostas obtidas nos instrumentos de coleta de dados.

Em relação à avaliação dos professores, todos consideraram os OA como instrumentos importantes no processo de ensino e aprendizagem. Além disso, contribuíram na avaliação com sugestões de melhorias para os OA.

Como estudos futuros pretende-se aprimorar os recursos elaborados de acordo com as sugestões dos alunos e professores e realizar estudos de caso com outros grupos de alunos. Em virtude do pequeno número de trabalhos sobre o Scratch no Ensino de Ciências e da importância dos mesmos, objetiva-se, também, desenvolver, experimentar e avaliar novos OA para o estudo de temas dessa área, em outros anos de escolaridade. 


\section{Referências}

ABNT (2003) "Engenharia de Software - Qualidade de produto: modelo de qualidade" NBR ISO/IEC 9126-1: 2003.

Almeida, R. R., Chaves, A. C. L., Araújo, C. A. C. F. de Jr (2012) “Avaliação de objetos de aprendizagem: aspectos a serem considerados neste processo", In: III Simpósio Nacional de Ensino de Ciência e Tecnologia - SINECT, Ponta GrossaParaná.

Batista, S. C. F., Barcelos, G. T.; Rapkiewicz, C. E. (2004) "Programas Educacionais: Desenvolvendo Posturas Críticas", In: Congresso Brasileiro de Informática na Educação - X Workshop de Informática na Escola - WIE, Salvador-Bahia.

Macêdo, L. N. de., Macêdo, A. A. M., Filho, J. A. de C. (2007) "Avaliação de um Objeto de Aprendizagem com Base nas Teorias Cognitivas", In: Congresso Brasileiro de Informática na Educação - XIII Workshop de Informática na Escola WIE, Rio de Janeiro.

Pensamento Digital (2012) "Iniciação à programação", http://oficinas.pensamentodigital.org.br/apostila_iniciacao_programacao.pdf, Setembro.

Primo, A. F. T, Cassol, M. B. F. (1999) "Explorando o conceito de interatividade: definições e taxonomias", Informática na Educação: teoria e prática, Rio Grande do Sul, Vol. 2, No. 2, pp. 65-80.

Resnick, M., Maloney, J., Monroy-Hernández, A.; Rusk, N., Eastmond, E., BRENNAN, K.; Millner, A., Rosenbaum, E., Silver, J., Silverman, B.; Kafai, Y. (2009) "Scratch: Programming for All", Communications of the ACM, Vol. 52, No. 11, pp. 60-67, 2009.

Rodrigues, G. S. de S. C., Colesanti, M. T. de M (2008) "Educação ambiental e as novas tecnologias de informação e comunicação", Revista Sociedade \& Natureza, Uberlândia, Vol. 20, No. 1, pp. 51-66.

Tarouco, L. (2004) “Avaliação de Objetos de Aprendizagem”, http://penta2.ufrgs.br/edu/objetosaprendizagem/, Agosto.

Trata Brasil (2012) "Ranking do Saneamento - Instituto Trata Brasil: nova metodologia e resultados", http://www.tratabrasil.org.br/datafiles/uploads/pdfs/relatorioranking.pdf>, Agosto. 